\title{
Effects of a speed of processing training intervention on self-reported health outcomes in breast cancer survivors
}

This article was published in the following Dove Press journal: Nursing: Research and Reviews

\author{
Jacqueline B Vo' \\ Pariya L Fazeli ${ }^{2,3}$ \\ Rachel Benz ${ }^{4}$ \\ Jennifer R Bail ${ }^{5}$ \\ Kristen Triebel $^{6}$ \\ David E Vance 3,4 \\ Karen Meneses ${ }^{4,7}, \dagger$ \\ 'Office of Research and Scholarship, \\ School of Nursing, University of Alabama, \\ Birmingham, AL 35294-I210, USA; \\ ${ }^{2}$ School of Nursing, University of \\ Alabama, Birmingham, AL, USA; ${ }^{3}$ Center \\ for Translational Research on Aging and \\ Mobility, University of Alabama, \\ Birmingham, AL, USA; ${ }^{4}$ Office of \\ Research and Scholarship, School of \\ Nursing, University of Alabama at \\ Birmingham, Birmingham, AL, USA; \\ ${ }^{5}$ Cancer Prevention and Control Training \\ Program, School of Health Professions, \\ University of Alabama at Birmingham, \\ Birmingham, AL, USA; ${ }^{6}$ Department of \\ Neurology, School of Medicine, \\ University of Alabama at Birmingham, \\ Birmingham, AL, USA; ${ }^{7}$ Comprehensive \\ Cancer Center, University of Alabama at \\ Birmingham, Birminghan, AL, USA \\ ${ }^{\dagger}$ Dr Karen Meneses passed away in \\ August 2018
}

Correspondence: Jacqueline B Vo Office of Research and Scholarship, School of Nursing, University of Alabama at Birmingham, 1720 Second Avenue South, Birmingham, AL 35294-1210, USA Email jacbui@uab.edu
Purpose: Cognitive deficits are a concern for breast cancer survivors, as these effects are prevalent and impact daily functioning and quality of life (QoL). The purpose of this study was to examine the effects of a speed of processing (SOP) training intervention on secondary, self-reported health outcomes in this population.

Methods: Sixty middle-aged and older adult women breast cancer survivors completed baseline assessments and were randomized to either a no-contact control group or an SOP training group, who completed $10 \mathrm{hrs}$ of computerized SOP training online at home. Both conditions completed self-report surveys of sleep, QoL, cognitive difficulties, and depressive symptoms at six weeks and six months post study entry.

Results: There were no significant effects of the SOP training on self-reported health outcomes.

Conclusion: Future studies examining the effect of cognitive training on self-reported health outcomes are warranted that include individuals with baseline impairment in such indices in order to better determine efficacy, and longer follow-up time points may aid in examining the protective effects of this intervention in those without baseline impairment.

Keywords: cancer survivorship, cognitive dysfunction, late effects, quality of life

\section{Introduction}

Breast cancer most commonly affects older women - with over two-thirds of new diagnoses occurring in women aged 55 and older. ${ }^{1}$ While treatment advances have significantly increased longevity, women living with breast cancer still experience deleterious effects as a result of treatment that can impact functioning and quality of life (QoL). ${ }^{2,3}$ One such effect is cognitive deficits, with incidence rates reported as high as $90 \%$. $^{4,5}$ This dysfunction has significant implications for daily living and independence in this population.

Despite the increased risk for cognitive deficits in this population, few studies have examined potential ways to mitigate such problems. Given the evidence of deficits in attention and speed of information processing (SOP) in this population, ${ }^{4,6-8}$ as well as the influence of these domains to successful performance in other cognitive domains, ${ }^{5}$ SOP may be an ideal intervention target. Briefly, computerized SOP training targets the ability to quickly attend to multiple stimuli simultaneously and accurately detect which stimuli were presented in a central and peripheral location on the screen amidst "distractors." Thus, within the larger domain of SOP, the training specifically targets visual attention including divided 
attention and selective attention. The training is tailored in that the presentation times of the stimuli are reduced as they are correctly identified, thus creating more challenge and scaffolding cognitive improvement. A few studies have examined a computerized SOP cognitive training protocol commonly used in the gerontological literature in breast cancer survivors and shown promising effects on improving this cognitive domain. ${ }^{9}$ A recent study by Meneses and colleagues ${ }^{10}$ showed positive effects in athome administered SOP training. Specifically, those in the SOP training group improved on measures of SOP and executive functioning compared to the control group. Previous studies in healthy older adults using this SOP training have shown positive translational effects over time on a diverse range of health outcomes, including mood, locus of control, QoL, and driving performance. ${ }^{11,12}$

The aim of the current study was to examine the effects of a home-based computerized SOP intervention on secondary, self-reported health outcomes (ie, self-reported depressive symptoms, sleep quality, perceived cognitive failures, and QoL) from the aforementioned SOP training study by Meneses et $\mathrm{al}^{10}$ in a diverse sample of middleaged and older women with breast cancer in the Deep South. Given improvements in previous studies, we explored the association between SOP training and specific health outcomes in this pilot study.

\section{Methods}

\section{Participants and procedure}

The Speed of Processing in Middle-Aged and Older Breast Cancer Survivors (SOAR) study was conducted through the School of Nursing at the University of Alabama at Birmingham (UAB) and was approved through the UAB Institutional Review Board (IRB) (\#141205005). Sixty participants were recruited from the greater Birmingham area through flyers and sign-up sheets at community and advocacy events geared towards breast cancer survivors. A consort diagram and details on sampling, recruitment, and eligibility criteria are described elsewhere. ${ }^{10}$ Eligible breast cancer survivors were scheduled for a baseline appointment at which they provided informed written consent. Assessments were conducted on UAB's campus at the Edward R. Roybal Center for Translational Research on Aging and Mobility.

A randomized-controlled study design was used. Participants completed a baseline assessment consisting of self-reported paper-and-pencil questionnaires as well as computer-based cognitive testing. The self-reported health outcomes assessed were measured using the Centers for Epidemiologic Studies Depression Scale, the Pittsburgh Sleep Quality Index, Cognitive Failures Questionnaire, and the Medical Outcomes Study Short-Form 36. Additionally, participants completed a sociodemographic and treatment questionnaire. Immediately following baseline assessment, participants were randomized into one of two groups: homebased computer SOP $(n=30)$ or no contact control $(n=30)$. After randomization, participants in the SOP group received a demonstration on accessing the online SOP training via the Brain HQ portal. Consistent with the therapeutic dose reported in the literature, ${ }^{11,12}$ participants were then assigned to complete $10 \mathrm{hrs}$ of training on this program at home over approximately 6 to 8 weeks, with a recommendation of $2 \mathrm{hrs}$ per week. Specifically, participants played the Double Decision game (brainhq.com). This program is tailored in that it increases the difficulty and speed of each trial as participants correctly complete each task. More information on the training program can be found in Meneses et al 2018. ${ }^{10}$ Participants in both groups returned for 6-week (posttest 1) and 6-month (posttest 2) follow-ups. Measures of the self-reported health outcomes for both follow-up assessments were completed at home prior to the appointment, while the cognitive measures were completed in person at the follow-up visits.

\section{Ethical approval}

All procedures performed in studies involving human participants were in accordance with the ethical standards of the institutional and/or national research committee and with the 1964 Helsinki declaration and its later amendments or comparable ethical standards.

\section{Informed consent}

Informed consent was obtained from all individual participants included in the study.

\section{Measures}

\section{Sociodemographic and treatment questionnaire}

This questionnaire contained 20 items. Sociodemographic data included age, race, education level, partner status, employment, income, and access to insurance. Cancer treatment questions included date of diagnosis, date of final treatment, surgery type, chemotherapy type, radiation therapy, and endocrine therapy. 


\section{Self-reported health outcomes \\ Centers for Epidemiologic Studies Depression Scale (CES-D)}

The CES-D was used to measure depressive symptomatology. The CES-D has been used extensively in research to determine risk of depression. The CES-D contains 20 items and was used as a symptom check-list for depressive symptoms. Each item was scored from 0 to 3 and summed to determine the total score, ranging from 0 to 60 . Participants had depressive symptoms if the total score was 16 or higher. For participants with missing data $(<5$ items), total scores were divided by total answered and multiplied by $20{ }^{13,14}$

\section{The Pittsburgh Sleep Quality Index (PSQI)}

The PSQI was administered to determine sleep quality and disturbance for each participant for the previous month. Nineteen items assessed perceived sleep quality, duration and latency of sleep, disturbances, sleep efficiency, use of medication, and a person's daytime dysfunction. A global score, ranging from 0 to 21 , determined sleep quality. Score of " 0 " indicated no difficulty and " 21 " indicates severe difficulties in all areas of sleep quality. ${ }^{15}$ Participants with missing data were excluded from the analyses due to inability to calculate global score.

\section{Cognitive Failures Questionnaire (CFQ)}

The CFQ was used to measure perceived cognitive impairment. This 25 -item self-reported scale measures general liability towards mistakes made in everyday life such as lapses in memory, perception, action, and control. The total score ranged from 0 to 100 , with a higher score indicating worse perceived cognitive impairment. ${ }^{16}$

\section{The Medical Outcomes Study Short-Form 36 (SF-36)}

The SF-36 was used to determine QoL through physical and mental health concepts. Thirty-six items assess eight QoL health constructs including limitations in physical and social activities because of: 1) physical functioning, 2) role limitations due to physical health, 3) role limitations due to mental health, 4) energy/fatigue, 5) emotional well-being, 6) social functioning, 7) pain, and 8) general health. Each health concept ranged from 0 to 100, with a higher score indicating better QoL. ${ }^{17}$ Participants who had missing data at the level of each health construct were excluded from the analyses due to the inability to calculate a score.

\section{Statistical analyses}

All data were analyzed using SPSS V-23. The significance level was set at 0.05 and was not corrected for multiple comparisons as this was a pilot study. Preliminary analyses were conducted to examine whether there were any group differences between sociodemographic characteristics, cancer treatment, and survivorship characteristics using independent sample $t$-tests or Pearson's chi-square tests when appropriate. $T$-tests were used to confirm that the two groups did not differ on baseline levels of any of the self-reported health outcome variables. Repeated measures $t$-tests were conducted for each self-reported health outcome separately within each group. If significant results were found, these were followed up with confirmatory analysis of covariance (ANCOVA) controlling for baseline levels for each of the self-reported health outcomes to determine whether there was a main effect of group. Finally, we examined whether controlling for any sociodemographic characteristics, cancer treatment, and survivorship characteristics that differed between groups influenced our initial pattern of results.

\section{Results}

Table 1 describes the study sample characteristics. The two groups did not differ on any of the self-reported health outcome variables at baseline. Paired $t$-tests conducted for each self-reported health outcome separately for each group showed the following changes: The control group had fewer cognitive symptoms (CFQ) from baseline to posttest $2(p<0.01)$, fewer role limitations due to emotional problems (SF-36 construct) from baseline to posttest 1 $(p<0.01)$, and better scores on energy/fatigue (SF-36 construct) from baseline to posttest $1(p=0.04)$. The intervention group had fewer cognitive symptoms (CFQ) from baseline to posttest $1(p<0.01)$ and from baseline to posttest $2(p<0.01)$, and better physical functioning (SF-36 construct) from baseline to posttest $2(p<0.01)$.

Table 2 reports the ANCOVAS controlling for baseline scores. ANCOVAS showed that there were no significant main effect of treatment between baseline and six-week posttest, and baseline and six-month posttest for either group for perceived cognitive impairment (CFQ), depressive symptoms (CES-D), and sleep quality (PSQI). For QoL (SF-36), the only statistically significant was a main effect of group for the role limitations due to emotional problems subscale $(p<0.05)$, such that the control group had fewer perceived role limitations due to emotional problems from baseline to immediate posttest. 
Table I Participant characteristics

\begin{tabular}{|c|c|c|c|c|}
\hline Variable & Total $(\mathrm{N}=60)$ & Control $(n=30)$ & Intervention $(n=30)$ & $p$ \\
\hline $\begin{array}{l}\text { Age } \\
\begin{array}{l}30-39 \\
40-49 \\
50-59 \\
60+\end{array}\end{array}$ & $\begin{array}{l}7(11.5 \%) \\
9(14.8 \%) \\
23(37.7 \%) \\
21(34.4 \%)\end{array}$ & $\begin{array}{l}4(13.3 \%) \\
2(6.7 \%) \\
12(40 \%) \\
12(40 \%)\end{array}$ & $\begin{array}{l}3(10 \%) \\
7(23.3 \%) \\
11(36.7 \%) \\
9(30 \%)\end{array}$ & 0.34 \\
\hline $\begin{array}{l}\text { Race } \\
\text { African American } \\
\text { Caucasian }\end{array}$ & $\begin{array}{l}31(51.7 \%) \\
29(48.3 \%)\end{array}$ & $\begin{array}{l}15(50 \%) \\
15(50 \%)\end{array}$ & $\begin{array}{l}16(53.3 \%) \\
14(46.7 \%)\end{array}$ & 0.80 \\
\hline $\begin{array}{l}\text { Partner Status } \\
\text { Living with partner } \\
\text { No partner }\end{array}$ & $\begin{array}{l}27(45 \%) \\
33(55 \%)\end{array}$ & $\begin{array}{l}10(33.3 \%) \\
20(66.7 \%)\end{array}$ & $\begin{array}{l}17(56.7 \%) \\
13(43.3 \%)\end{array}$ & 0.07 \\
\hline $\begin{array}{l}\text { Religion } \\
\text { Christian } \\
\text { Other } \\
\text { Missing }\end{array}$ & $\begin{array}{l}5 \mathrm{I}(85 \%) \\
7(11.7 \%) \\
2(3.3 \%)\end{array}$ & $\begin{array}{l}26(86.7 \%) \\
3(10 \%) \\
I(3.3 \%)\end{array}$ & $\begin{array}{l}25(83.3 \%) \\
4(13.3 \%) \\
I(3.4 \%)\end{array}$ & 0.69 \\
\hline Education (years) & 15.3 (SD 2.7) & $15.5($ SD 2.4) & I5.I (SD 2.9) & 0.60 \\
\hline $\begin{array}{l}\text { Employment } \\
\text { Employed } \\
\text { Unemployed } \\
\text { Retired/Disabled }\end{array}$ & $\begin{array}{l}31(51.7 \%) \\
6(10 \%) \\
23(38.3 \%)\end{array}$ & $\begin{array}{l}17(56.7 \%) \\
2(6.7 \%) \\
11(36.6 \%)\end{array}$ & $\begin{array}{l}17(56.7 \%) \\
4(13.3 \%) \\
12(40 \%)\end{array}$ & 0.61 \\
\hline $\begin{array}{l}\text { Family Income } \\
\quad<\$ 30,000 \\
>\$ 30,000 \\
\text { Do not care to respond } \\
\text { Missing }\end{array}$ & $\begin{array}{l}14(23.3 \%) \\
37(61.7 \%) \\
7(11.7 \%) \\
2(3.3 \%)\end{array}$ & $\begin{array}{l}7(23.3 \%) \\
20(66.7 \%) \\
3(10 \%) \\
0\end{array}$ & $\begin{array}{l}7(23.3 \%) \\
17(56.7 \%) \\
4(13.3 \%) \\
2(6.7 \%)\end{array}$ & 0.50 \\
\hline $\begin{array}{l}\text { Medications } \\
\text { Depression } \\
\text { Sleep } \\
\text { Anxiety }\end{array}$ & $\begin{array}{l}15(25 \%) \\
24(40 \%) \\
20(33.3 \%)\end{array}$ & $\begin{array}{l}5(16.7 \%) \\
11(36.7 \%) \\
9(30 \%)\end{array}$ & $\begin{array}{l}10(33.3 \%) \\
13(43.3 \%) \\
11(36.7 \%)\end{array}$ & $\begin{array}{l}0.14 \\
0.60 \\
0.58\end{array}$ \\
\hline $\begin{array}{l}\text { Health Insurance } \\
\text { Insured } \\
\text { Not Insured }\end{array}$ & $\begin{array}{l}58(96.7 \%) \\
2(3.3 \%)\end{array}$ & $\begin{array}{l}29(96.7 \%) \\
\text { I (3.3\%) }\end{array}$ & $\begin{array}{l}29(96.7 \%) \\
\text { I (3.3\%) }\end{array}$ & 1 \\
\hline Survivorship (years) & $5.8(5.5)$ & $6.2(5.4)$ & $5.3(5.7)$ & 0.60 \\
\hline $\begin{array}{l}\text { Breast Cancer Treatment } \\
\text { Chemotherapy } \\
\text { Radiation } \\
\text { Hormone Therapy } \\
\text { Lumpectomy } \\
\text { Mastectomy }\end{array}$ & $\begin{array}{l}51(85 \%) \\
39(65 \%) \\
32(53.3 \%) \\
21(35 \%) \\
37(61.7 \%)\end{array}$ & $\begin{array}{l}25(83.3 \%) \\
15(50 \%) \\
14(46.7 \%) \\
6(20 \%) \\
23(76.7 \%)\end{array}$ & $\begin{array}{l}26(86.7 \%) \\
24(80 \%) \\
18(60 \%) \\
15(50 \%) \\
14(46.7 \%)\end{array}$ & $\begin{array}{l}0.72 \\
0.02 \\
0.30 \\
0.01 \\
0.01\end{array}$ \\
\hline
\end{tabular}

Note: $p$-values in bold are indicative of significance at $p<0.05$.

Given that the groups differed on surgery type (lumpectomy vs mastectomy), radiation status (radiation vs no radiation), and trended towards a difference on living with partner status (yes or no) (see Table 1), we controlled for these variables in the aforementioned ANCOVAs. Further, while the groups did not differ on percent with depression scores in the clinical range ( $\geq 16$ on CES-D) given the potential importance of 
Table 2 Self-reported health outcomes among control and intervention groups

\begin{tabular}{|c|c|c|c|c|c|c|c|c|}
\hline \multirow[t]{3}{*}{ Variable } & \multicolumn{3}{|c|}{ Control $(n=30)$} & \multicolumn{3}{|c|}{ Intervention $(n=30)$} & \multirow[t]{3}{*}{$p^{\prime}$} & \multirow[t]{3}{*}{$p^{2}$} \\
\hline & Baseline & Posttest I & Posttest 2 & Baseline & Posttest I & Posttest 2 & & \\
\hline & \multicolumn{3}{|c|}{ Mean (SD) } & \multicolumn{3}{|c|}{ Mean (SD) } & & \\
\hline Depression & $15.9(9.7)$ & $15.7(8.7)$ & I4.4 (II) & $18.4(10.4)$ & $14.8(9.6)$ & $15(11.1)$ & 0.13 & 0.55 \\
\hline \% Depressed ( $\geq 16$ years) & 53.3 & 55.6 & 46.4 & 60 & 44.8 & 44.8 & & \\
\hline Sleep quality & $9.5(4.1)$ & $7.8(4.2)$ & $8.3(4.4)$ & $9(4.1)$ & $8.8(4.5)$ & $8.4(3.8)$ & 0.25 & 0.57 \\
\hline Perceived Cognitive Failures & $56.3(14.8)$ & $52.7(14.4)$ & $48.9(12.8)$ & $55.6(12.9)$ & $49.8(15.2)$ & $45.1(16.1)$ & 0.33 & 0.16 \\
\hline \multicolumn{9}{|l|}{ Health concepts } \\
\hline Physical functioning & $69(26.8)$ & $67.4(28.3)$ & $72(25)$ & $61.8(24.8)$ & $68.1(25.3)$ & $72.1(22.3)$ & 0.25 & 0.22 \\
\hline $\begin{array}{l}\text { Role limitations due to } \\
\text { physical health }\end{array}$ & $59.2(4 \mid .8)$ & $55.6(46.7)$ & $67.9(4 \mid .3)$ & $41.7(4 \mid .2)$ & $50.9(43.5)$ & $56(44.1)$ & 0.49 & 0.96 \\
\hline $\begin{array}{l}\text { Role limitations due to } \\
\text { emotional problems }\end{array}$ & $54.4(39.6)$ & $81.5(32.5)$ & $64.3(39.5)$ & $44.4(37.5)$ & $57.5(4 \mid .7)$ & $49.4(40.5)$ & $<0.05$ & 0.31 \\
\hline Energy/Fatigue & $46.2(23.8)$ & $52.2(24.8)$ & $51.3(24.6)$ & $39.7(20.9)$ & $44.1(25)$ & $45.7(25.2)$ & 0.61 & 0.87 \\
\hline Emotional well-being & $68.4(2 \mathrm{I})$ & $69(19.8)$ & $68(18.1)$ & $67.7(17.6)$ & $68.7(20)$ & $69(19.4)$ & 0.93 & 0.62 \\
\hline Social functioning & $69.2(27.8)$ & $75.9(23.7)$ & $75(26.4)$ & $64.6(24.4)$ & $69(24)$ & $72(24.5)$ & 0.45 & 0.99 \\
\hline Pain & $63.3(22.0)$ & $65.6(25.1)$ & $68.6(26.3)$ & $61.3(28.9)$ & $62.6(29.9)$ & $65.4(27.8)$ & 0.58 & 0.58 \\
\hline General health & $62.2(19.4)$ & $63.7(19.4)$ & $68.4(18.2)$ & $62.4(20.8)$ & $64(20.1)$ & $65.5(22.8)$ & 0.93 & 0.37 \\
\hline
\end{tabular}

Notes: $p$-values in bold are indicative of ANCOVA main effect with significance at $p<0.05$. $p^{\prime}$ : Differences in groups from baseline to posttest I. $p^{2}$ : Differences in groups from baseline to posttest 2 .

depressive symptoms on intervention engagement and on the self-reported health outcomes, we entered this binary depression variable into the models as well. All original ANCOVA results remained unchanged when including these covariates, such that there was no main effect for condition.

\section{Discussion}

The goal of the current study was to examine whether an SOP training intervention showed positive effects on selfreported health outcomes in a sample of breast cancer survivors. Overall, we did not find that this intervention yielded positive effects on such outcomes, including perceived cognitive impairment, depressive symptoms, sleep quality, and QoL. This may have largely been due to a relatively healthy and cognitively unimpaired sample at baseline, which was unexpected given this clinical population. For example, the study inclusion criteria for this pilot study did not explicitly require that participants have functional or cognitive impairment at baseline, which may have limited the ability to detect an effect on selfreported health outcomes. Additionally, the sample of breast cancer survivors was younger compared to studies in which self-reported health outcomes improved. ${ }^{18,19}$

Furthermore, our short 6-month follow-up period may not have allowed for examination of the protective effect of this intervention on future declines in these healthrelated outcomes. In other words, 6 months may not be enough time for functional declines to emerge in a sample that is relatively healthy at baseline. For example, in the large multi-site ACTIVE study, those in the SOP training group were less likely to have clinically relevant drops in QoL and less likely to experience clinically important increases in depressive symptoms at 5 years post intervention compared to the control group, ${ }^{18,19}$ suggesting the intervention helped to avoid or slow the rate of functional decline. Long term, we may expect a similar protective effect on $\mathrm{QoL}^{20}$ or these self-reported health outcomes. As such, future work in this sample should include longer follow-up times to examine the potential effect of this intervention over time but may also include older participants with functional or cognitive impairment at baseline to examine immediate therapeutic effects.

The current study had many strengths. First, this study is one of the first and only studies to examine the effect of a cognitive intervention self-reported health outcomes in older breast cancer survivors. Second, the randomized controlled design was a strength. Third, this study included a diverse sample of older breast cancer survivors, particularly in the Deep South. Given that many cancer clinical trials lack minority representation and studies have demonstrated barriers to minority participation, ${ }^{21}$ we felt that our sample of 
approximately half being African American was a strength. Lastly, retention in the current study was very high (96\%).

Nonetheless, this small pilot study is not without limitations, the first of which being the small sample size, limiting power to detect significant effects. Another limitation is that our two groups differed on some cancer-related factors (eg, treatment type), and while we did adjust for these factors, future studies should employ a stratified randomization to ensure that groups are balanced on cancer factors such as stage and treatment at the onset of the study. Furthermore, given that participants were community-dwelling breast cancer survivors and we did not explicitly recruit (eg, in clinical settings) those with poorer functioning in this population, this possibly resulted in a selection bias, resulting in ceiling effects on the self-reported health outcomes for some of the participants at baseline, such that they were performing well on these measures prior to the intervention. Future intervention studies targeting similar health outcomes in this population should screen for and include participants with impairments in such outcomes in order to determine feasibility, acceptability, and efficacy in those who are most at risk, with the ultimate goal of determining how best to disseminate such training to those who may derive the greatest benefit. Related, the current study only followed up participants for 6 months, which may not have allowed for determining the protective effect of this intervention on self-reported health outcomes. For example, in the ACTIVE study where participants were not functionally impaired at baseline, immediate improvements on these outcomes were not found, whereas over time the training reduced the slope of decline, suggesting a preventative effect as compared to the control group. ${ }^{20}$ Thus, future studies warrant a longer follow-up time frame.

\section{Conclusion}

This study did not demonstrate improvements in overall, self-reported health outcomes (ie, depressive symptoms, sleep quality, perceived cognitive failures, and QoL) among breast cancer survivors as a result of SOP training. This pilot study had shorter follow-up and a younger and relatively healthy sample which may have contributed to not finding immediate improvements in health outcomes. Future studies should consider 1) requiring cognitive impairment at baseline and 2) longer follow-up to assess long-term improvements in these secondary health outcomes.

\section{Acknowledgments}

The authors acknowledge Dr. Jennifer Frank for her editorial assistance and work with this study. This article is dedicated to the memory of Karen Meneses, PhD, RN, FAAN, renowned nurse scientist and beloved Professor and Associate Dean for Research in the University of Alabama at Birmingham School of Nursing, who died suddenly of natural causes on August 1, 2018. She was an internationally recognized pioneering expert in breast cancer survivorship and cancer disparities. The authors gratefully acknowledge the following support for this project from the Center for Translational Research on Aging and Mobility, Edward R. Roybal Center Project and funding from the National Institute on Aging (P30 AG022838; Ball: PI; Meneses Pilot PI). Jacqueline B Vo was supported by the Robert Wood Johnson Foundation Future of Nursing Scholars Program (\#72592), Susan G. Komen Graduate Training in Disparities Research (GTDR15329376), and an American Cancer Society Doctoral Degree Scholarship in Cancer Nursing (DSCN-17-076-01). Dr. Wheeler was supported by the National Institute on Aging (R00 AG048762). Dr. Bail was supported by an American Cancer Society Doctoral Degree Scholarship in Cancer Nursing (DSCN-16-066-01) and Susan G Komen Graduate Training in Disparities Research (GTDR 15329376). Dr. Triebel was supported by the American Cancer Society (MRSG-14-204-01). Dr. Vance was supported by National Institute(s) of Health grants from National Institute of Mental Health (5R01MH106366$02)$ and National Institute of Nursing Research (1R21NR016632-01).

\section{Disclosure}

Dr. Vance has served as a paid consultant for Posit Science, Inc.; the software used for the SOP training in this study. A conflict of interest statement for Dr Karen Meneses is not available. The authors report no other conflicts of interest in this work.

\section{References}

1. American Cancer Society. Breast Cancer Facts \& Figures 2017-2018. Atlanta: American Cancer Society; 2017.

2. Fu MR, Axelrod D, Guth AA, et al. Comorbidities and quality of life among breast cancer survivors: a prospective study. Pers Med. 2015;5 (3):229-242. doi:10.3390/jpm5030229

3. Hsu T, Ennis M, Hood N, Graham M, Goodwin PJ. Quality of life in long-term breast cancer survivors. J Clin Oncol. 2013;31 (28):3540-3548. doi:10.1200/JCO.2012.48.1903

4. Frank JS, Vance DE, Jukkala A, Meneses KM. Attention and memory deficits in breast cancer survivors: implications for nursing practice and research. $J$ Neurosci Nurs. 2014;46(5):274-284. doi:10.1097/ JNN.0000000000000078 
5. Jansen CE, Cooper BA, Dodd MJ, Miaskowski CA. A prospective longitudinal study of chemotherapy-induced cognitive changes in breast cancer patients. Support Care Cancer. 2011;19(10):1647-1656. doi:10.1007/s00520-010-0997-4

6. Adams-Price CE, Morse LW, Cross GW, Williams M, Wells-Parker E. The effects of chemotherapy on useful field of view (UFOV) in younger and older breast cancer patients. Exp Aging Res. 2009;35:220-234. doi:10.1080/03610730902720497

7. Collins B, MacKenzie J, Tasca GA, Scherling C, Smith A. Cognitive effects of chemotherapy in breast cancer patients: a dose-response study. Psycho-Oncology. 2013;22:1517-1527. doi:10.1002/pon.3163

8. Koppelmans V, Bretler M, Boogerd W, Seynaeve C, Gundy C, Schagen SB. Neuropsychological performance of breast cancer more than 20 years after adjuvant chemotherapy. J Clin Oncol. 2012;30(10):1080-1986. doi:10.1200/JCO.2011.37.0189

9. Von Ah D, Carpenter JS, Saykin A, et al. Advanced cognitive training for breast cancer survivors: a randomized controlled trial. Breast Cancer Res Treat. 2012;135(3):799-809. doi:10.1007/s10549-012-2210-6

10. Meneses K, Benz R, Bail JR, et al. Speed of processing training in middle-aged and older breast cancer survivors (SOAR): results of a randomized controlled pilot. Breast Cancer Res Treat. 2017;1-9. doi:10.1007/s10549-017-4564-2

11. Ball K, Berch DB, Helmers KF, et al. Effects of cognitive training interventions with older adults: a randomized controlled trial. JAMA. 2002;288:2271-2281. doi:10.1001/jama.288.18.2271

12. Ball KK, Ross LA, Roth DL, Edwards JD. Speed of processing training in the ACTIVE study: how much is needed and who benefits? J Aging Health. 2013;25(8S):65S-84S. doi:10.1177/0898264312470167

13. Eaton WW, Muntaner C, Smith C, Tien A, Ybarra M. Center for epidemiologic studies depression scale: review and revision (CESD and CESD-R). In: Maruish ME, editor. The Use of Psychological Testing for Treatment Planning and Outcomes Assessment. 3rd ed. New Jersey: Lawrence Erlbaum; 2004:363-377.
14. Radloff LS. The CES-D scale: a self-report depression scale for research in the general population. Appl Psychol Meas. 1977;1:385-401. doi:10.1177/014662167700100306

15. Buysse DJ, Reynolds CF, Monk TH, Berman SR, Kupfer DJ. The pittsburgh sleep quality index: a new instrument for psychiatric practice and research. Psychiatry Res. 1989;28 (2):193-213

16. Broadbent DE, Cooper PF, FitzGerald P, Parkes KR. The cognitive failures questionnaire (CFQ) and its correlates. Br J Clin Psychol. 1982;21(1):1-16.

17. Ware JE, Sherbourne CD. The MOS 36-item short-form health survey (SF-36): I. Conceptual framework and item selection. Med Care. 1992;473-483. doi:10.1097/00005650-19920600000002

18. Wolinsky FD, Unverzagt FW, Smith DM, Jones R, Tennstedt SL. The ACTIVE cognitive training trial and health-related quality of life: protection that lasts for 5 years. J Gerontology Ser A. 2006;61 (12):1324-1329. doi:10.1093/gerona/61.12.1324

19. Wolinsky FD, Vander Weg MW, Martin R, et al. The effect of speed-of-processing training on depressive symptoms in ACTIVE. $J$ Gerontology Ser A. 2009;64(4):468-472. doi:10.1093/gerona/ gln044

20. Wolinsky FD, Unverzagt FW, Smith DM, Jones R, Wright E, Tennstedt SL. The effects of the ACTIVE cognitive training trial on clinically relevant declines in health-related quality of life. J Gerontology Ser B. 2006;61(5):S281-7. doi:10.1093/geronb/61.5. $\mathrm{S} 281$

21. Hamel LM, Penner LA, Albrecht TL, Heath E, Gwede CK, Eggly S. Barriers to clinical trial enrollment in racial and ethnic minority patients with cancer. Cancer Control. 2016;23(4):327-337. doi: $10.1177 / 107327481602300404$

\section{Publish your work in this journal}

Nursing: Research and Reviews is an international, peer-reviewed, open access journal publishing original research, reports, reviews and commentaries on all aspects of nursing and patient care. These include patient education and counseling, ethics, management and organizational issues, diagnostics and prescribing, health outcomes, economics and resource management, improving patient safety in all settings. The manuscript management system is completely online and includes a very quick and fair peer-review system. Visit http://www. dovepress.com/testimonials.php to read real quotes from published authors. 